\title{
Conocimientos adquiridos por padres en un programa educativo de reanimación cardiopulmonar básica pediátrica
}

\author{
PAOLA PINO A. ${ }^{1}$, ANDRÉS CASTILLO M. ${ }^{2}$ \\ 1. Enfermera. Servicio de Pediatría. Hospital Clínico Pontificia Universidad Católica de Chile. \\ 2. Profesor Asistente. División de Pediatría. Unidad de Paciente Crítico Pediátrica. Hospital Clínico Pontificia Universidad \\ Católica de Chile.
}

\begin{abstract}
Outcome of a parent education program on basic pediatric cardiopulmonary resuscitacion

Background: Most pediatric cardiac arrest episodes are the result from extra cardiac events. They occur at home, while children are under the supervision of their parents or caregivers. Therefore pediatric health care providers should promote the education of basic pediatric cardiopulmonary resuscitation (CPR) to parents. Objective: To describe the outcome of an educational program of basic pediatric CPR to parents of admitted children. Patients and Method: 108 parents of 89 patients admitted to the pediatric Service of the Clinical Center Universidad Catolica were provided with CPR training. Acquired knowledge was assessed through a phone survey, consistent in 6 questions with a maximum score of 14 points, applied 1 month after the training session. Results: Median score obtained was 12 points. Five participants achieved a score of 14 points. Least retained knowledge related to: steps of CPR $(31.5 \%)$, number of cycles before activating an emergency system $(55.6 \%)$, and steps followed when removing foreign body airway obstruction in conscious children (14.8\%). Conclusions: In this study, only a few participants were able to answer all six questions without mistakes. However, hard-to-remember concepts were identified, for emphasis in future educational programs.

(Key words: Knowledge, training, cardiopulmonary resuscitation, parent).

Rev Chil Pediatr 2012; 83 (3): 224-230
\end{abstract}

\section{RESUMEN}

Antecedentes: En pediatría, la mayoría de los paros cardiorrespiratorios son de origen extra cardíaco y se producen en el hogar, donde los niños se encuentran bajo la supervisión de sus padres o cuidadores. Por lo anterior, los profesionales de la salud infantil deberían promover la capacitación a los padres en reanimación cardiopulmonar (RCP) básica pediátrica. Objetivo: Evaluar los conocimientos adquiridos por los padres de niños hospitalizados luego de un programa educativo de RCP básica pediátrica. Pacientes y Método: Se

Trabajo recibido el 04 de agosto de 2011, devuelto para corregir el 27 de noviembre de 2011, segunda versión 28 de diciembre de 2011, aceptado para publicación el 04 de febrero de 2012

Correspondencia a:

Paola Pino A.

E-mail:pspino@uc.cl 
realizó un estudio descriptivo para identificar los conocimientos adquiridos por 108 padres de 89 pacientes hospitalizados, en un programa educativo implementado en el Servicio de Pediatría del Hospital Clínico UC. El instrumento utilizado fue una encuesta de 6 preguntas con un puntaje máximo de 14 puntos, aplicada telefónicamente un mes después del taller. Resultados: El puntaje obtenido presentó una mediana de 12 puntos. Cinco participantes obtuvieron el puntaje total. Las preguntas con menos porcentaje de cumplimiento fueron las referentes a los pasos para realizar RCP (31,5\%), al número de ciclos antes de activar el sistema de emergencias $(55,6 \%$ ) y a los pasos para aliviar la asfixia por cuerpo extraño en niños conscientes $(14,8 \%)$. Conclusión: En este estudio, un bajo porcentaje de los participantes estudiados fue capaz de responder las 6 preguntas sin errores. Por otro lado, se logró identificar los conceptos que fueron más difíciles de recordar para los participantes; los cuales deben ser abordados con más énfasis en futuros programas educativos.

(Palabras clave: Conocimiento, capacitación, reanimación cardiopulmonar, padres).

Rev Chil Pediatr 2012; 83 (3): 224-230

\section{Introducción}

El paro cardiorrespiratorio (PCR) es el cese de la actividad mecánica cardíaca, que se caracteriza por falta de respuesta, apnea y ausencia de pulsos centrales ${ }^{1}$. Es una de las principales causas de muerte en Norte América y se estima que en Estados Unidos aproximadamente 330000 personas mueren cada año antes de llegar a un hospital o en la sala de urgencias².

En pediatría, el PCR súbito es mucho menos común que en los adultos y ocurre principalmente en niños con enfermedad cardíaca de base o antecedentes de arritmia. Durante la lactancia y la niñez, la mayoría de los PCR son de origen extra cardíaco y se producen en el hogar y sus alrededores, donde los niños se encuentran bajo la supervisión de sus padres o cuidadores. En este contexto, los cuadros como síndrome de muerte súbita del lactante, traumatismo, asfixia por inmersión, intoxicación, asfixia por cuerpo extraño, asma grave y neumonía son las causas más frecuentes de PCR en pediatría ${ }^{3}$.

Una vez que ocurre el PCR, incluso con esfuerzos óptimos de resucitación, el resultado suele ser malo. En el ámbito extra hospitalario, sólo entre el 5\% y $12 \%$ de los niños que presentan un PCR sobreviven hasta el alta ${ }^{1}$. Sin embargo, la American Heart Association (AHA) sugiere que la morbilidad y mortalidad del PCR extra hospitalario podría reducirse en forma significativa si el $20 \%$ de la población pudiera realizar reanimación cardiopulmonar $(\mathrm{RCP})^{4}$.

Por lo anterior, los profesionales de la sa- lud infantil deberían ser los responsables de promover la capacitación a los padres en RCP básica pediátrica, en especial a las familias de niños que necesitan cuidados de salud especiales, dados de alta de unidades intensivas neonatales, que tienen acceso a piscinas o que practican deportes acuáticos ${ }^{5}$.

En Chile, existen programas educativos de RCP básica pediátrica para padres, en el sector público y privado; sin embargo, no existen publicaciones acerca del nivel de conocimientos y habilidades adquiridas por los participantes. Además, no hay difusión con respecto a capacitación en maniobras para aliviar la asfixia por cuerpo extraño.

El objetivo del estudio es describir los conocimientos adquiridos por los padres de niños hospitalizados luego de un programa educativo de RCP básica pediátrica.

\section{Pacientes y Método}

Estudio descriptivo implementado en el Servicio de Pediatría del Hospital Clínico Universidad Católica (UC). La muestra correspondió a 108 padres de 89 niños hospitalizados en la Unidad de Paciente Crítico Pediátrico, los cuales cumplían con los siguientes criterios de inclusión: diagnóstico de ingreso asociado a riesgo de presentar un PCR en el hogar; paciente con al menos 24 horas de extubación; interés de los padres en participar, y ausencia de instrucción previa en un período de 2 años.

El programa educativo fue implementado entre los meses de mayo y septiembre de 
año 2010, en sesiones individuales para cada paciente, donde podían asistir ambos padres y otros cuidadores, con una duración de 30 a 60 min., dependiendo del número de participantes. Para este fin, se utilizó una sala destinada para procedimientos y educación de familiares. La instrucción fue siempre realizada por la misma enfermera.

Previo al taller, se entregaron dos folletos educativos: "Reanimación cardiopulmonar básica pediátrica" y "Maniobras para aliviar la asfixia por cuerpo extraño", ambos según la edad del paciente. Estos folletos fueron elaborados para el presente estudio, según los criterios de la AHA y revisados por la Directora del Centro de Entrenamiento UC en Reanimación Básica, previo a la actualización de las recomendaciones realizada en noviembre de 2010.

El objetivo general del programa educativo fue desarrollar habilidades para realizar RCP básica pediátrica en los padres de niños hospitalizados con riesgo de presentar un PCR en el hogar. Las actividades fueron planificadas según el modelo de educación participativa de Jane Vella ${ }^{6}$ :

- Tareas de inducción: Introducción al tema, identificando la importancia de la educación, según el factor de riesgo del paciente.

- Tareas de input: Exposición verbal de definición, incidencia, pronóstico, etiología, causas, prevención y signos de PCR. Exposición verbal de los signos de obstrucción severa de la vía aérea.

- Tareas de implementación: Demostración de las maniobras de RCP, según la edad del paciente; luego cada participante realiza las maniobras de RCP. Demostración de las maniobras para aliviar la asfixia por cuerpo extraño, según la edad del paciente; luego cada participante realiza las maniobras para aliviar la asfixia por cuerpo extraño.

- Tareas de integración: Cierre del tema, evaluando la utilidad del aprendizaje, según los factores de riesgo del paciente. Cada participante se compromete a mantener los folletos educativos en un lugar accesible para toda la familia y a reforzar los contenidos en el hogar.
Tabla 1. Pauta de evaluación del conocimiento adquirido y su puntaje

\begin{tabular}{|lll|}
\hline n & $\begin{array}{l}\text { Preguntas evaluadas en la encuesta } \\
\text { de conocimiento }\end{array}$ & Puntaje \\
\hline 1 & Definición de paro cardiorrespiratorio & 2 puntos \\
\hline 2 & Signos de paro cardiorrespiratorio & 2 puntos \\
\hline 3 & $\begin{array}{l}\text { Pasos para realizar reanimación } \\
\text { cardiopulmonar }\end{array}$ & 5 puntos \\
\hline 4 & $\begin{array}{l}N^{\circ} \text { de ciclos antes de activar el sistema } \\
\text { de emergencias }\end{array}$ & 1 punto \\
\hline 5 & $\begin{array}{l}\text { Pasos para aliviar la asfixia por cuerpo } \\
\text { extraño en niños conscientes }\end{array}$ & 3 puntos \\
\hline 6 & $\begin{array}{l}\text { Maniobra para aliviar la asfixia por cuerpo } \\
\text { extraño en niños inconscientes }\end{array}$ & 1 punto \\
\hline
\end{tabular}

Al finalizar la capacitación, se evaluó la habilidad para realizar la RCP y las maniobras para aliviar la asfixia por cuerpo extraño. Todos los participantes debían aprobar esta evaluación antes de retirarse de la sala.

La evaluación del aprendizaje se realizó a partir de 4 semanas posteriores a la instrucción, en forma telefónica, aplicando una encuesta de conocimiento de 6 preguntas, con un puntaje máximo de 14 puntos (tabla 1). El instrumento de evaluación fue elaborado para el presente estudio, según los criterios de la AHA y revisado por la Directora del Centro de Entrenamiento UC en Reanimación Básica, previo a la actualización de las recomendaciones realizada en noviembre de 2010.

Los datos fueron recolectados de la ficha médica y una entrevista telefónica. Las variables estudiadas fueron: sexo, edad, previsión de salud y diagnóstico de ingreso de los pacientes, parentesco con el niño, edad y escolaridad de los participantes, tiempo trascurrido entre el taller y la evaluación del conocimiento y conocimiento adquirido.

Para el análisis de los datos se utilizó el Programa SPSS. Se realizaron medidas de tendencia central y dispersión, y análisis de frecuencia. Se contó con el consentimiento informado de todos los participantes.

\section{Resultados}

Durante el programa educativo fueron entrenados 108 padres de 89 niños hospitalizados 
Tabla 2. Distribución porcentual del cumplimiento según cada pregunta evaluada

\begin{tabular}{|c|c|c|c|}
\hline \multirow[t]{2}{*}{$\mathbf{n}$} & \multirow{2}{*}{$\begin{array}{l}\text { Preguntas evaluadas en la encuesta de } \\
\text { conocimiento }\end{array}$} & \multicolumn{2}{|c|}{ Cumplimiento } \\
\hline & & $\%$ & $\mathbf{n}$ \\
\hline 1 & Definición de paro cardiorrespiratorio & 93,5 & 101 \\
\hline 2 & Signos de paro cardiorrespiratorio & 90,7 & 98 \\
\hline 3 & Pasos para realizar reanimación cardiopulmonar & 31,5 & 34 \\
\hline 4 & $\begin{array}{l}N^{\circ} \text { de ciclos antes de activar el sistema de } \\
\text { emergencias }\end{array}$ & 55,6 & 60 \\
\hline 5 & Pasos para aliviar la asfixia en niños conscientes & 14,8 & 16 \\
\hline 6 & $\begin{array}{l}\text { Maniobra para aliviar la asfixia en niños incons- } \\
\text { cientes }\end{array}$ & 92,6 & 100 \\
\hline
\end{tabular}

Tabla 3. Distribución porcentual del cumplimiento según cada paso para realizar reanimación cardiopulmonar

\begin{tabular}{|llcc|}
\hline n & $\begin{array}{l}\text { Pasos para realizar reanimación } \\
\text { cardiopulmonar }\end{array}$ & \multicolumn{2}{c|}{ Cumplimiento } \\
\hline 1 & Evaluar el estado de conciencia & n \\
\hline 2 & Permeabilizar la vía aérea & 91,7 & 99 \\
\hline 3 & Evaluar la respiración & 74,1 & 80 \\
\hline 4 & Administrar 2 ventilaciones & 81,5 & 88 \\
\hline 5 & Administrar 30 compresiones cardíacas & 63,9 & 69 \\
\hline
\end{tabular}

Tabla 4. Distribución porcentual del cumplimiento según cada paso para aliviar la asfixia por cuerpo extraño en niños conscientes menores de 1 año

\begin{tabular}{|llcc|}
\hline n & $\begin{array}{l}\text { Pasos para aliviar la asfixia por cuerpo } \\
\text { extraño }\end{array}$ & \multicolumn{2}{c|}{ Cumplimiento } \\
\hline 1 & Sentarse con el niño en su regazo & \% & n \\
\hline 2 & Administrar 5 palmadas en la espalda & 35,6 & 65 \\
\hline 3 & Administrar 5 compresiones en el tórax & 41,2 & 25 \\
\hline $\mathrm{n}=68$ & & \\
\hline
\end{tabular}

Tabla 5. Distribución porcentual del cumplimiento según cada paso para aliviar la asfixia por cuerpo extraño en niños conscientes mayores de 1 año

\begin{tabular}{|llcc|}
\hline n & $\begin{array}{l}\text { Pasos para aliviar la asfixia por cuerpo } \\
\text { extraño }\end{array}$ & \multicolumn{2}{c|}{ Cumplimiento } \\
\hline 1 & Hincarse o pararse detrás del niño & 95 & 38 \\
\hline 2 & Colocar correctamente los brazos y el puño & 97,5 & 39 \\
\hline $3 \quad$ Administrar 5 compresiones en el abdomen & 17,5 & 7 \\
\hline $\mathrm{n}=40$. & & \\
\hline
\end{tabular}

que cumplieron con los criterios de inclusión. Del total de niños, 57,3\% correspondían al sexo masculino, la edad promedio fue 1,7 años $( \pm 2,6$ años), $60,7 \%$ de ellos menores de 1 año, $55,1 \%$ tenían Isapre como previsión de salud. Según el diagnóstico de ingreso, $42,7 \%$ fue hospitalizado por patología cardiaca, $30,3 \%$ por patología neurológica y $27 \%$ por patología respiratoria.

Del total de participantes, $78,7 \%$ correspondían a madres y el resto a padres, la edad promedio fue $31,2 \pm 8$ años. Según la escolaridad, 9,3\% había cursado su último año en la enseñanza básica, $26,9 \%$ en la enseñanza media y $63,8 \%$ tenían algún tipo de estudio superior.

El tiempo transcurrido entre el taller y la evaluación del conocimiento presentó un rango entre 25 y 117 días, con una mediana de 35 días. E1 conocimiento adquirido fue evaluado a través de la encuesta telefónica, el puntaje obtenido presentó un rango entre 3 y 14 puntos, con una mediana de 12 puntos. El porcentaje de cumplimiento de cada pregunta se ilustra en la tabla 2. Cinco participantes obtuvieron el puntaje máximo. Las preguntas 3, 4 y 5 obtuvieron porcentaje de cumplimiento menor a $90 \%$, siendo la pregunta 5 la de menor cumplimiento.

El porcentaje de cumplimiento de cada paso para realizar reanimación cardiopulmonar, se ilustra en la tabla 3. El 31,5\% de los participantes realizaría los 5 pasos descritos. Los pasos con menos cumplimiento fueron: administrar 2 ventilaciones y administrar 30 compresiones cardíacas; ya que, si bien la mayoría de los participantes señaló ambos pasos $(97,2 \%$ y $98,1 \%$ respectivamente), un porcentaje bajo recordó el número correcto (63,9\% y $65,7 \%$ respectivamente).

El porcentaje de cumplimiento de cada paso para aliviar la asfixia por 
cuerpo extraño en niños conscientes menores de 1 año, se ilustra en la tabla 4. El 14,8\% de los participantes realizaría los 3 pasos descritos. Los pasos con menos cumplimiento fueron: administrar 5 golpes en la espalda y administrar 5 compresiones en el tórax. Si bien la mayoría de los participantes señaló los golpes en la espalda $(95,6 \%)$, un porcentaje bajo recordó el número correcto $(36,8 \%)$. Cabe destacar que la mitad de los participantes señaló las compresiones en el tórax $(54,4 \%)$.

El porcentaje de cumplimiento de cada paso para aliviar la asfixia por cuerpo extraño en niños conscientes mayores de 1 año, se ilustra en la tabla 5. El 15\% de los participantes realizaría los 3 pasos descritos. El paso con menos cumplimiento fue: administrar 5 compresiones en el abdomen, si bien la mayoría de los participantes lo señaló $(97,5 \%)$, un porcentaje bajo recordó el número correcto $(17,5 \%)$.

\section{Discusión}

En este estudio, un bajo porcentaje de los participantes estudiados fue capaz de responder las seis preguntas sin errores. Por otro lado, se logró identificar los conceptos que fueron más difíciles de recordar para los participantes, entre éstos se encuentran: la proporción correcta entre ventilaciones y compresiones cardiacas, el número de ciclos antes de activar el sistema de emergencias, la proporción entre golpes en la espalda y compresiones en el tórax para aliviar la asfixia por cuerpo extraño en niños conscientes, menores de un año; y el número de compresiones en el abdomen en niños mayores de un año. Estos conceptos deben ser abordados con más énfasis en futuros programas educativos, ya que son más fáciles de olvidar si no se practican, lo cual refuerza la idea de simplificar al máximo las maniobras, sugerencias ya consideradas en las recomendaciones realizadas por la AHA en noviembre de $2010^{7}$.

Las variables estudiadas, parentesco con el niño, edad y escolaridad de los participantes son similares a las encontradas en otros estudios, donde la mayoría de los asistentes fueron madres, con un promedio de edad entre 30 y 35 años y con algún tipo de estudio superior ${ }^{8,9,10}$.
En cuanto a los días trascurridos entre el taller y la evaluación del conocimiento, en el grupo estudiado existió una gran variabilidad; sin embargo, la evaluación en todos los participantes fue hecha luego de un período mayor a 3 semanas. Lo anterior difiere de lo publicado por Brannon y cols, donde los participantes fueron evaluados inmediatamente después de la intervención ${ }^{9}$. Esta variable pudo influir en los resultados; ya que, el rango de días trascurridos fue amplio, y la literatura refiere que el conocimiento y la confianza para realizar RCP disminuyen significativamente a medida que pasa el tiempo desde el último entrenamiento ${ }^{8}$.

En relación al conocimiento adquirido, los resultados del estudio son similares a los publicados por $\mathrm{Cu}$ y cols, quienes evaluaron a 348 padres, de los cuales $53 \%$ tenía capacitación previa en RCP; ellos encontraron que el $70 \%$ de los participantes evaluaría el estado de conciencia, el $74 \%$ permeabilizaría la vía aérea, y sólo el 11\% realizaría 2 ventilaciones y 30 compresiones cardiacas ${ }^{8}$. Esto confirma que, el concepto más difícil de recordar para los participantes es la proporción entre ventilaciones y compresiones, hallazgo muy relevante considerando que ésta era la base del entrenamiento en RCP según las guías de la AHA 2006, especialmente en niños en donde el paro hipóxico es el más relevante ${ }^{1,2}$. Sin embargo, se debe destacar que tal como lo señalan las recomendaciones 2010, todo reanimador lego con entrenamiento debe al menos aplicar compresiones cardíacas a la víctima de un PCR, si además puede realizar ventilación de rescate, debe aplicar compresiones y ventilaciones con una relación de 30:27.

La metodología utilizada para este estudio fue la capacitación convencional con instructor. En la investigación de Brannon y cols, se compara la efectividad de la instrucción convencional utilizando un vídeo previo al taller. Los resultados fueron significativos, ya que el grupo que utilizó el vídeo obtuvo una tasa de aprobación de $100 \%$ versus el $69 \%$ obtenido por el grupo con instrucción convencional. Además, el 80\% del grupo intervención calificó bien en los 3 pasos de la RCP (evaluación, ventilación y compresiones) versus el $18,7 \%$ del grupo control ${ }^{9}$. Si bien es un estudio peque- 
ño (23 participantes), la intervención utilizada podría ser útil para mejorar la retención de los conocimientos en futuros programas educativos, ya que esta metodología además entrega mayor homogeneidad al entrenamiento.

Dentro de las fortalezas del presente estudio se encuentran la baja variabilidad en la enseñanza, dado que el programa educativo fue ejecutado por una instructora y aplicando la misma metodología en la totalidad de los participantes. Esto permite lograr una continuidad del entrenamiento y evitar la variación propia del cambio de operador.

Dentro de las limitaciones del estudio se encuentran, que la habilidad para realizar las maniobras sólo fue evaluada al finalizar la capacitación y no al mes después, momento en el cual sólo fue evaluada el área cognitiva del aprendizaje, debido al costo que significa volver a citar a los participantes. Además, la gran variabilidad en el tiempo transcurrido entre el taller y la evaluación del conocimiento no permitió realizar otro tipo de análisis, debido al sesgo que esta variable podría generar en los resultados.

En conclusión, se recomienda a los profesionales de la salud infantil, capacitar en RCP básica pediátrica al menos a todos los padres de niños con riesgo de presentar un PCR en el hogar, incluso como pre requisito para el alta, para así aumentar el número de legos que puedan realizar RCP de mejor calidad. Los futuros programas educativos debieran integrar idealmente a todos los pacientes hospitalizados y sumar las recomendaciones 2010, ya que los cambios establecidos en éstas simplifican el entrenamiento de los reanimadores legos, destacando la necesidad de administrar pronto compresiones cardíacas a la víctima de un PCR y por otro lado, es importante integrar una educación universal en RCP de tal manera que todos seamos capaces de actuar ante una emergencia, especialmente si ocurre con los más cercanos.

Esta evaluación, es la primera que se realiza en el Servicio de Pediatría del Hospital Clínico UC, se continuará con una investigación cuasi experimental para evaluar la eficacia de un programa educativo para padres de niños hospitalizados, utilizando el vídeo de instruc- ción para familiares y amigos de la AHA, incorporando las recomendaciones 2010 y las áreas cognitiva, psicomotora y afectiva del aprendizaje a través del tiempo.

\section{Agradecimientos}

A la E.M. Olga Garrido, Coordinadora Área Materno Infantil. Hospital Clínico UC; quien facilitó los recursos para la realización del programa educativo.

A la Dra. Guiliana Córdova, Directora de BLS. Centro de Entrenamiento UC; quien realizó la revisión de los folletos educativos y de la encuesta de conocimiento.

Al Dr. Jaime Cerda, Especialista en Salud Pública. Departamento de Salud Pública UC; quien realizó el análisis estadístico de los datos.

A la PhD María Teresa Urrutia, Profesora Asociada. Escuela de Enfermería UC; quien supervisó la redacción del manuscrito.

\section{Referencias}

1.- American Heart Association: Evaluación pediátrica. En: SVAP libro para el proveedor, Barcelona: Editorial Prous Science, 2006; 1-32.

2.- American Heart Association: Conceptos generales. En: SVB para el personal del equipo de salud, Barcelona: Editorial Prous Science, 2006; 1-2.

3.- American Heart Association: Apoyo vital básico pediátrico. En: AVB para profesionales de la salud, Argentina: Asociación Civil de Producción y Desarrollo en Salud, 2002; 133-78.

4.- Connolly M, Toner P, Connolly D, McCluskey D: The "ABC for Life" Programme-teaching basic life support in schools. Resuscitation 2007; 72: 270-9.

5.- Committee on Pediatric Emergency Medicine: Role of pediatricians in advocating life support training courses for parent and the public. Pediatrics 2004; 114 (6): 1676.

6.- Montero J: Educación Participativa de adultos. El modelo dialogante de Jane Vella. Experiencia en Chile. Revista de Estudios Médicos Humanísticos 2007; 15: (15).

7.- Berg M, Schexnayder S, Chameides L, et al: Part 13: Pediatric Basic Life Support: 2010 American Heart Association Guidelines for Cardiopulmonary Resuscitation 
and Emergency Cardiovascular Care. Circulation. 2010; 122 (3): S862-S875.

8.- $\quad C u$ J, Phan P, O'Leary, F: Knowledge and attitude towards pediatric cardiopulmonary resuscitation among the carers of patients attending the emergency Department of the Children's Hospital at Westmead. Emerg Med Australas 2009; 21 (5): 401-6.

9.- Brannon T, White L, Kilcrease J, Richard L, Spillers J,
Phelps C: Use of instructional video to prepare parents for learning infant cardiopulmonary resuscitation. Proc (Bayl Univ Med Cent) 2009; 22 (2): 133-7.

10.- Dracup K, Moser D, Doering L, Guzy P, Juarbe T: A controlled trial of cardiopulmonary resuscitation training for ethnically diverse parents of infants at high risk for cardiopulmonary arrest. Crit Care Med. 2000; 28 (9): 3289-95. 